\title{
Mechanisms and Intermediates in the True Liquid Crystal Templating Synthesis of Mesoporous Silica Materials
}

\section{- Supporting Information -}

Johanna R. Bruckner ${ }^{1}$, Jessica Bauhof ${ }^{1}$, Jacqueline Gebhardt ${ }^{1}$, Ann-Katrin Beurer ${ }^{2}$, Yvonne Traa $^{2}$ and Frank Giesselmann ${ }^{1}$

${ }^{1}$ Institute of Physical Chemistry, University of Stuttgart, Pfaffenwaldring 55, 70569 Stuttgart, Germany

${ }^{2}$ Institute of Technical Chemistry, University of Stuttgart, Pfaffenwaldring 55, 70569 Stuttgart, Germany

List of content:

1. Shear viscosities of the lyotropic liquid crystal parent systems ..................................... 2

2. Additional small angle X-ray scattering data of the lyotropic liquid crystal parent systems .. 3

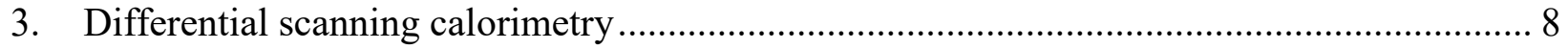

4. Additional small and wide angle X-ray scattering data of the templating process .............. 10

5. Additional transmission electron micrographs …..................................................... 16

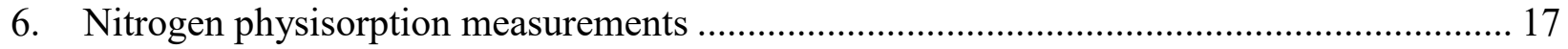

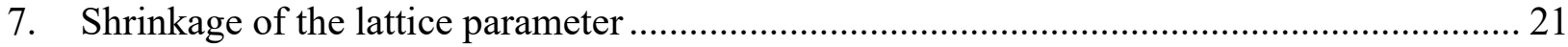

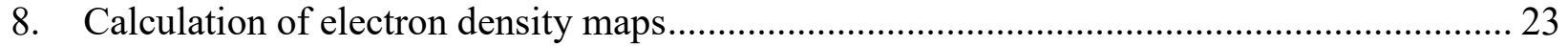




\section{Shear viscosities of the lyotropic liquid crystal parent systems}

Shear viscosities were measured with a Physica MCR 501 rheometer from Anton Paar and the associated software RheoPlus. All measurements were performed at $25{ }^{\circ} \mathrm{C}$ in a cone-plate geometry (CP50-1/TG, diameter: $50 \mathrm{~mm}$, angle: $\left.1^{\circ}\right)$. The measurement protocol includes 31 points with a measurement time of $5 \mathrm{~s}$ each in a shear rate range between $0.1 \mathrm{~s}^{-1}$ and $200 \mathrm{~s}^{-1}$. Due to the varying phase symmetries present in the three samples, different alignment effects were observed during shearing. Thus, for better comparability, all samples were presheared once with the same protocol as used for the actual measurements.

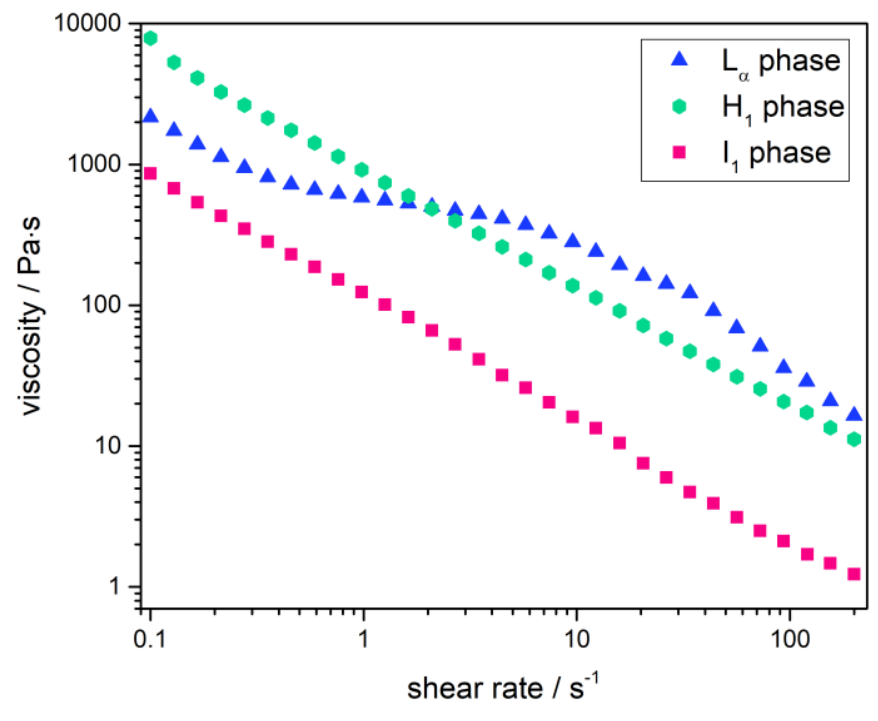

Figure S1. Shear viscosities of the lyotropic liquid crystal parent systems measured at room temperature with $w(\mathrm{P} 123)=27.5 \mathrm{wt} . \%$ for the cubic $\mathrm{I}_{1}$ phase, $w(\mathrm{P} 123)=45 \mathrm{wt} . \%$ for the hexagonal $\mathrm{H}_{1}$ phase and $w(\mathrm{P} 123)=70 \mathrm{wt} . \%$ for the lamellar $\mathrm{L}_{\alpha}$ phase. 


\section{Additional small angle $X$-ray scattering data of the lyotropic liquid crystal parent systems}

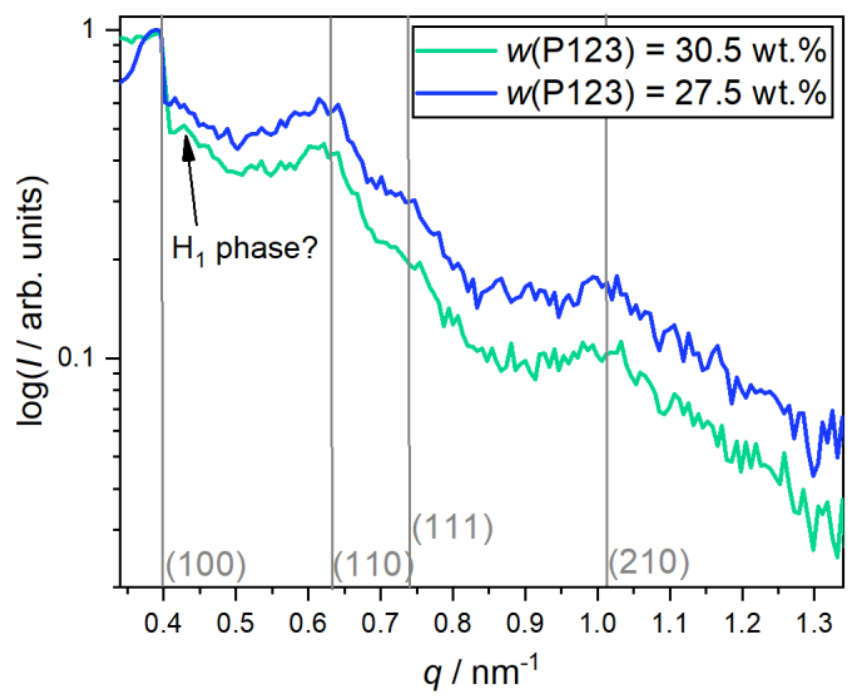

Figure S2. SAXS patterns of the cubic $\mathrm{I}_{1}$ phase with $w(\mathrm{P} 123)=30.5 \mathrm{wt} . \%$ and $w(\mathrm{P} 123)=27.5 \mathrm{wt} . \%$. Even though the two scattering curves look almost identical, the sample with the higher polymer concentration exhibits birefringence, which hints at a two-phase regime with the hexagonal $\mathrm{H}_{1}$ phase. Additionally, a small increase of the scattered intensity occurs at $q=0.43 \mathrm{~nm}^{-1}$ for the sample with $w(\mathrm{P} 123)=30.5 \mathrm{wt} . \%$, which matches almost perfectly with the (100) reflection of the $\mathrm{H}_{1}$ phase. 

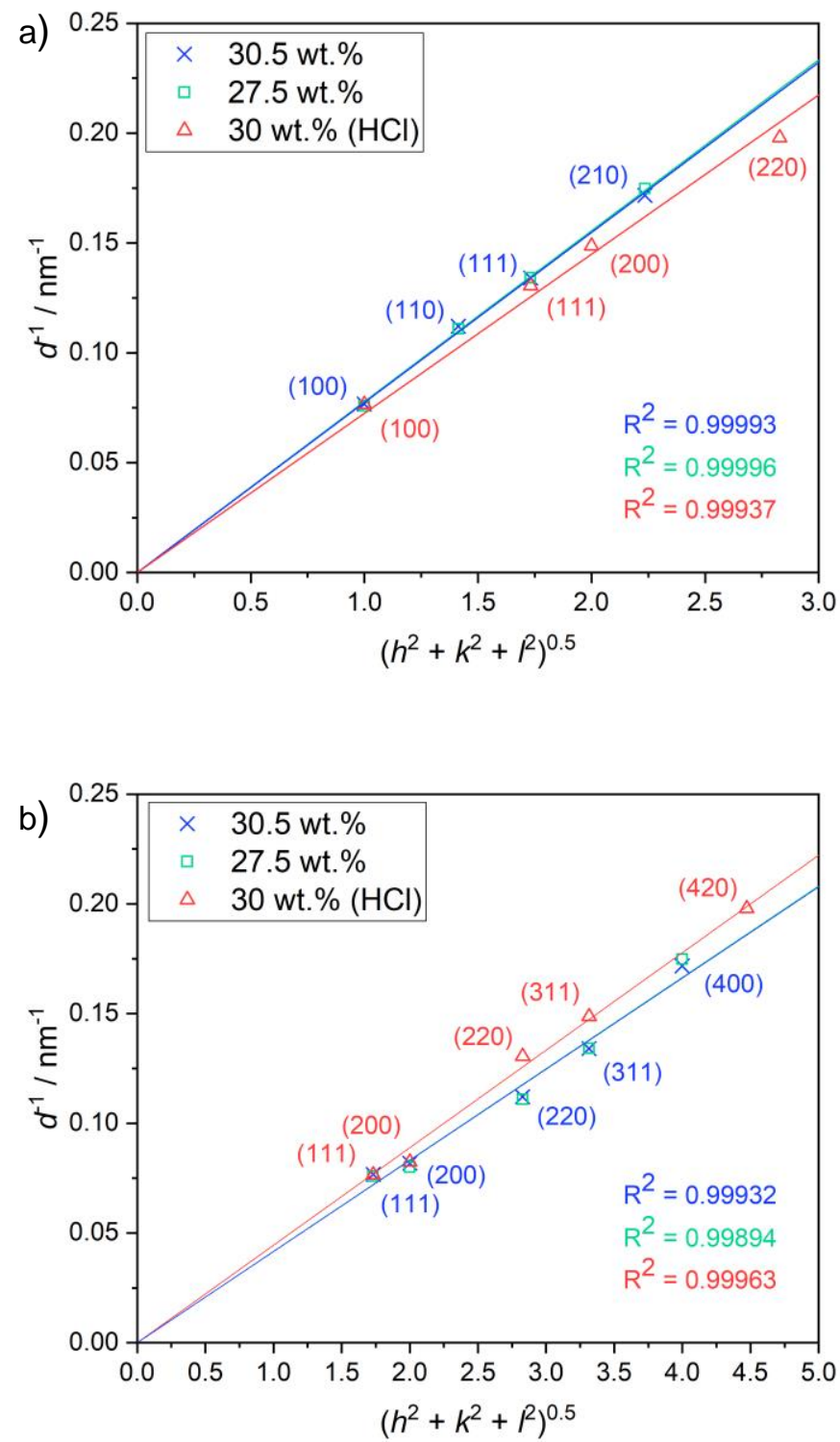

Figure S3. The scattering peaks of the $\mathrm{I}_{1}$ phase (cf. Figures S2 and S4) may either be assigned to a) a primitive cubic or b) a face centered cubic lattice. The level of compliance correlates with the value of $\mathrm{R}^{2}$ derived from linear regression. In case of the two samples with water the primitive cubic lattice matches much better. The sample prepared with $0.1 \mathrm{~N}$ hydrochloric acid and $w(\mathrm{P} 123)=30 \mathrm{wt} . \%$ exhibits a slightly better fit with the face centered cubic lattice. 


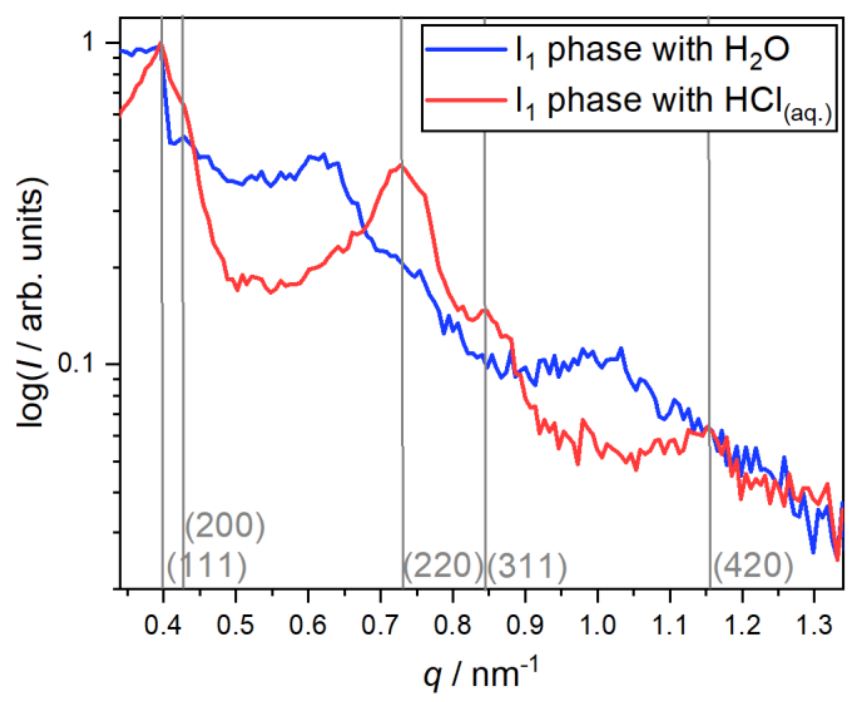

Figure S4. SAXS patterns of the cubic $\mathrm{I}_{1}$ phase with $w(\mathrm{P} 123)=30.5 \mathrm{wt} . \%$ in double distilled water and $w(\mathrm{P} 123)=30 \mathrm{wt} . \%$ in $0.1 \mathrm{~N}$ hydrochloric acid. The scattering maxima of the acidified sample seem to shift to higher $q$-values compared to the aqueous sample. This could either indicate an increase of the primitive cubic lattice constant from $12.9 \mathrm{~nm}$ (aqueous) to $13.5 \mathrm{~nm}$ (acidified) or a transition to a face centered cubic for which the Miller's Indices are shown in grey. In the latter case, the lattice parameter would be $22.7 \mathrm{~nm}$. The change of the structure might either be due to a stronger solvation of the ethylene glycol moieties in the presence of hydronium or to an altered concentration in the $\mathrm{I}_{1}$ phase caused by the possible phase separation into an $\mathrm{I}_{1}$ phase and a $\mathrm{H}_{1}$ phase. 


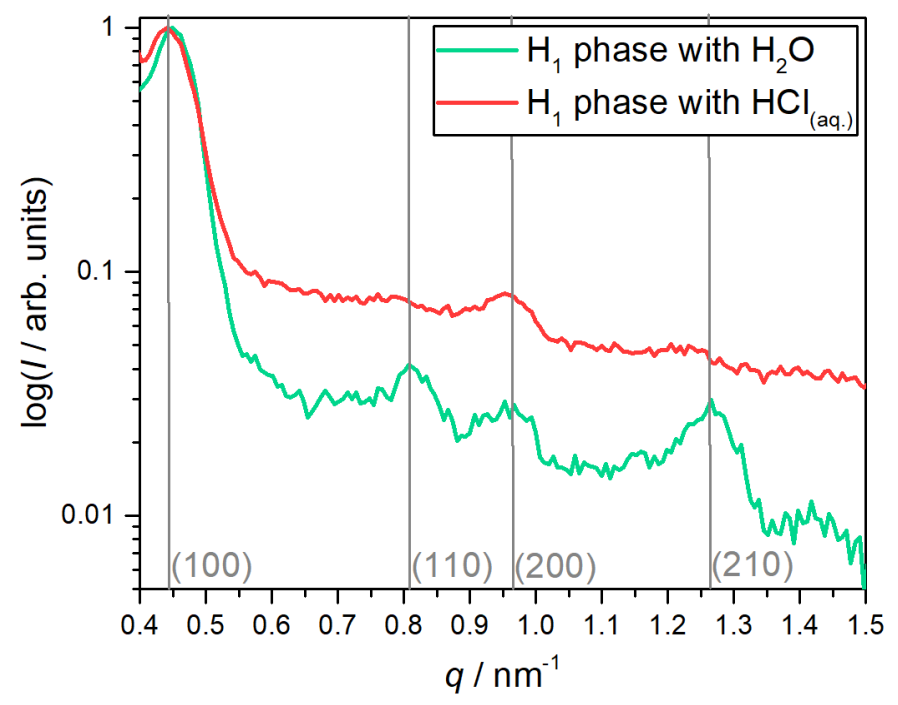

Figure S5. SAXS patterns of the hexagonal $\mathrm{H}_{1}$ phase with double distilled water and diluted hydrochloric acid $(\mathrm{pH}=1)$ both with $w(\mathrm{P} 123)=45 \mathrm{wt} . \%$, show almost no difference, except for variation of the relative peak intensities. This variation is due to the comparably electron-rich chloride ions, which alter the electron density distribution and thus the structure factor of the sample. 


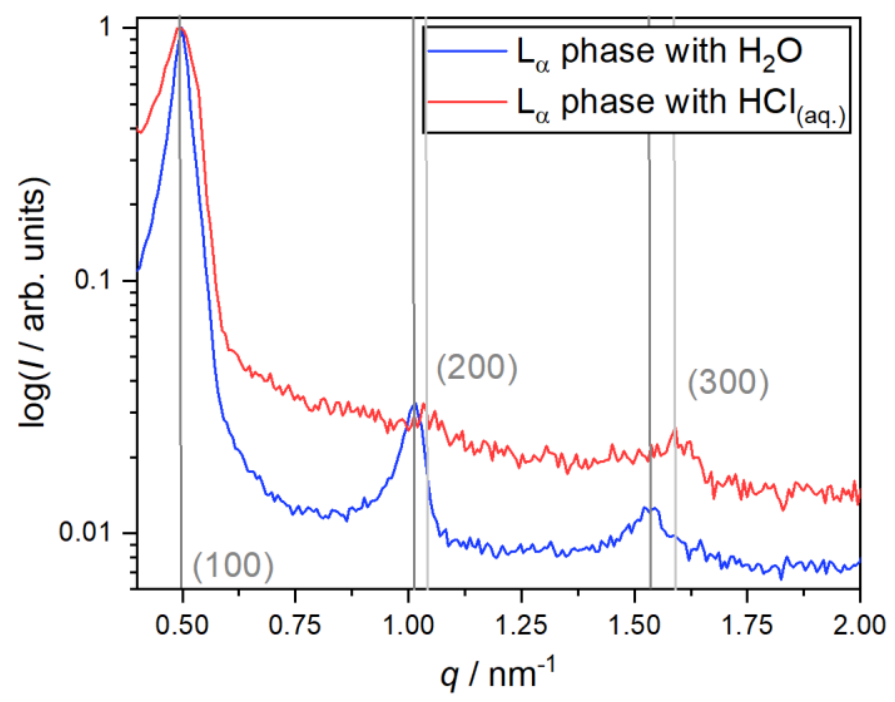

Figure S6. SAXS curves of the lamellar $\mathrm{L}_{\alpha}$ phases with $w(\mathrm{P} 123)=70 \mathrm{wt} . \%$ and double distilled water as well as with $w(\mathrm{P} 123)=71 \mathrm{wt} . \%$ and hydrochloric acid with $\mathrm{pH}=1$. The variation of the diffraction intensities might be due to the same reasons as discussed for Figure S5, while the slight shift of the $q$-values originates from the slight difference in concentrations. 


\section{Differential scanning calorimetry}

$2 \mathrm{mg}$ to $5 \mathrm{mg}$ of of each LLC sample were filled in aluminium pans (PerkinElmer, part number B0169321) sealed and measured with a DSC 8000 from PerkinElmer. For each sample three meausurement cycles were performed with a speed of $5{ }^{\circ} \mathrm{C} \cdot \mathrm{min}^{-1}$. For analysis the second heating and cooling cycles were used. No degradation of the samples within the measurement range was detected.

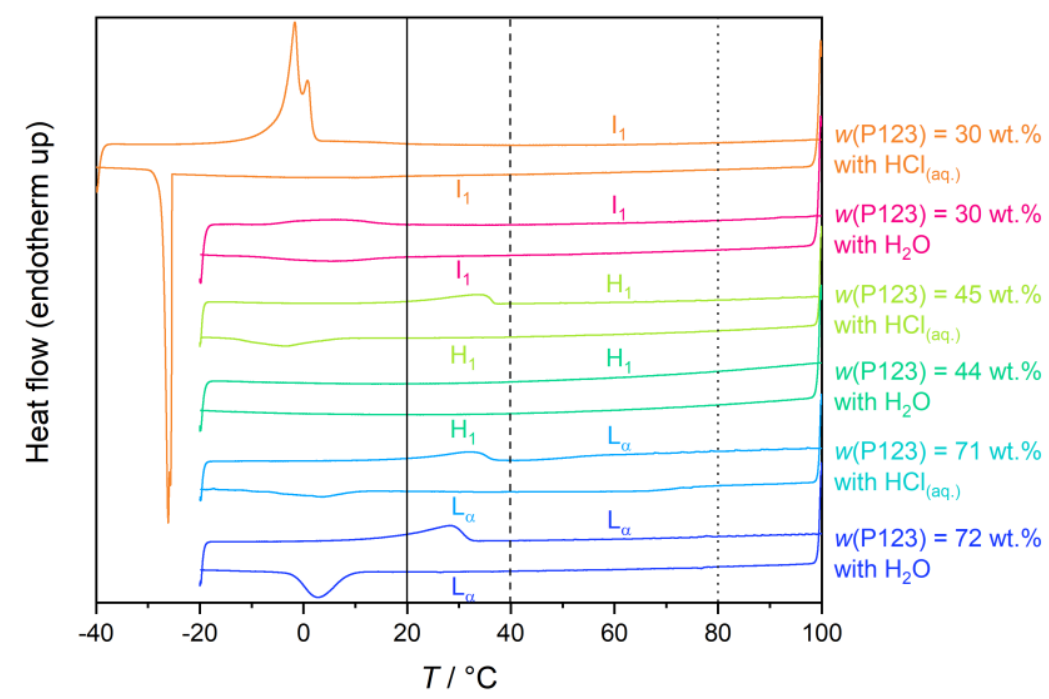

Figure S7. Heat flow of the LLC parent systems with water and $0.1 \mathrm{~N}$ hydrochloric acid. All samples were measured from $-20{ }^{\circ} \mathrm{C}$ to $100{ }^{\circ} \mathrm{C}$ except for the sample with $w(\mathrm{P} 123)=30 \mathrm{wt} . \%$ and hydrochloric acid, which was measured from $-40{ }^{\circ} \mathrm{C}$ to $100^{\circ} \mathrm{C}$. The sharp peaks in this curve originate from a transition to a crystalline phase. All other curves only exhibit a broad endothermic maximum, which might be associated to the micellization process. Considering that the LLC samples were heated to $40{ }^{\circ} \mathrm{C}$ for mixing (dashed line) and were never cooled below $20{ }^{\circ} \mathrm{C}$ (solid line) this process should not affect the templating performed at $80^{\circ} \mathrm{C}$ (dotted line). 


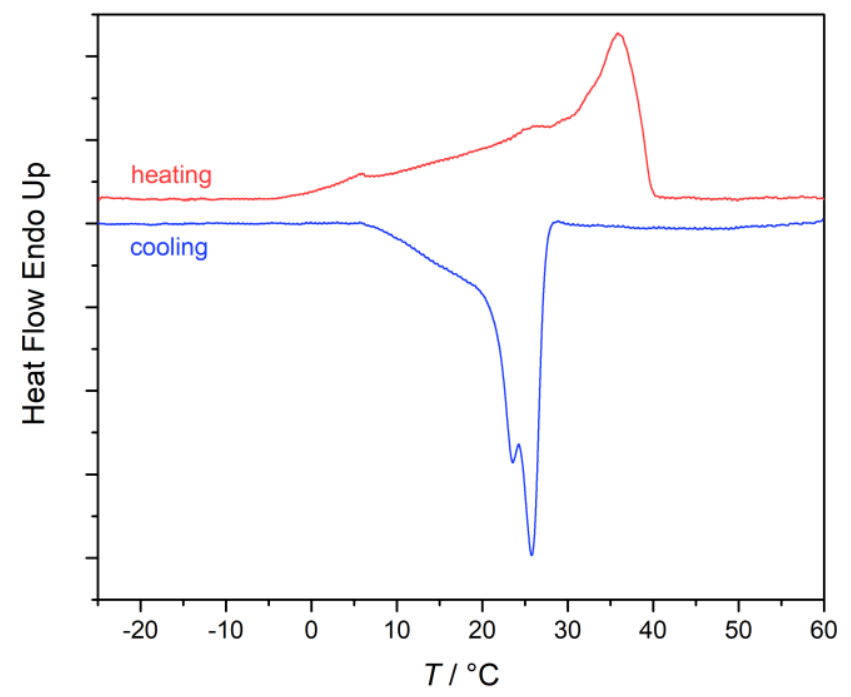

Figure S8. Heat flow of the used surfactant P123 measured with $5^{\circ} \mathrm{C} \cdot \mathrm{min}^{-1}$; the third heating and cooling cycle are shown. Due to its polymeric nature, no sharp phase transitions occur, however, it is evident, that the melting process is completed below $40{ }^{\circ} \mathrm{C}$. 


\section{Additional small and wide angle $X$-ray scattering data of the templating process}

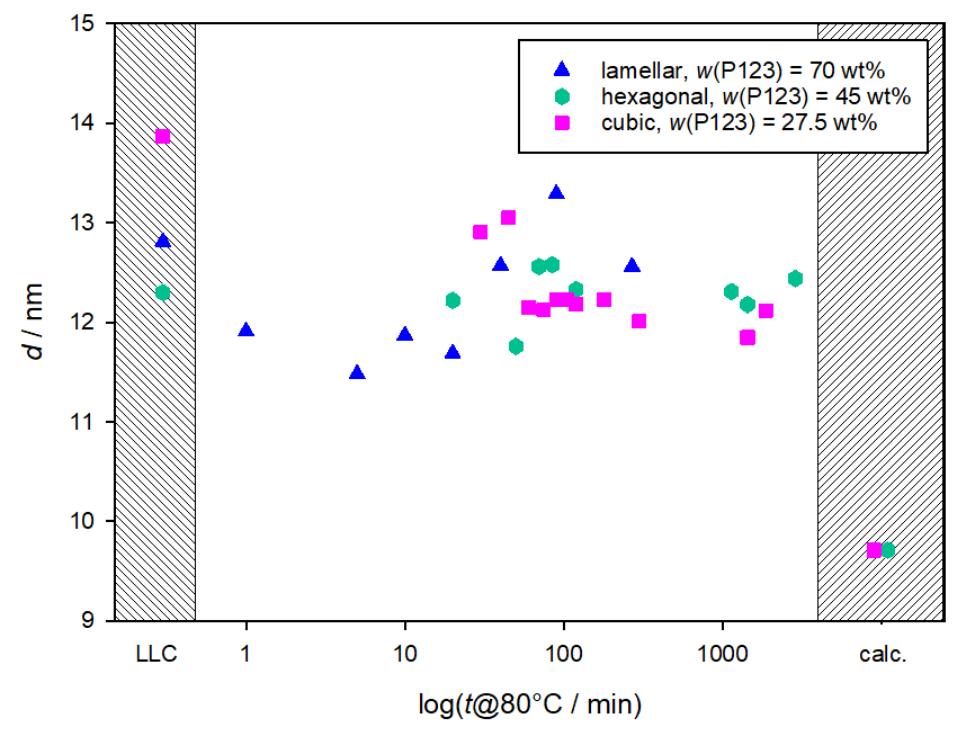

Figure S9. Temporal evolution of the periodicity distance $d$ corresponding to the first scattering maximum of the three investigated systems during the templating process. The corresponding periodicity distances of the calcined materials and of the lyotropic liquid crystal parent systems are also depicted. In case of the system with the lamellar $\mathrm{L}_{\alpha}$ phase as parent system, no scattering maximum was present after calcination, which suggests a collapse of the structure. 
Wide angle X-ray scattering (WAXS) measurements were performed, using the same sample preparation technique as described above, with a Bruker AXS NanoSTAR-System and the associated software $\mathrm{SAXS}$. $\mathrm{Cu}-\mathrm{K}_{\alpha}$ radiation was generated by a Kristalloflexx $770 \mathrm{X}$-ray generator $(40 \mathrm{kV}, 35 \mathrm{~mA})$ from Siemens and monochromatized as well as focused with two Göble mirrors. The distance from the sample to the Hi Star 2D detector with a resolution of 1024 pixel $\mathrm{x}$ 1024 pixel was calibrated with silver behenate.

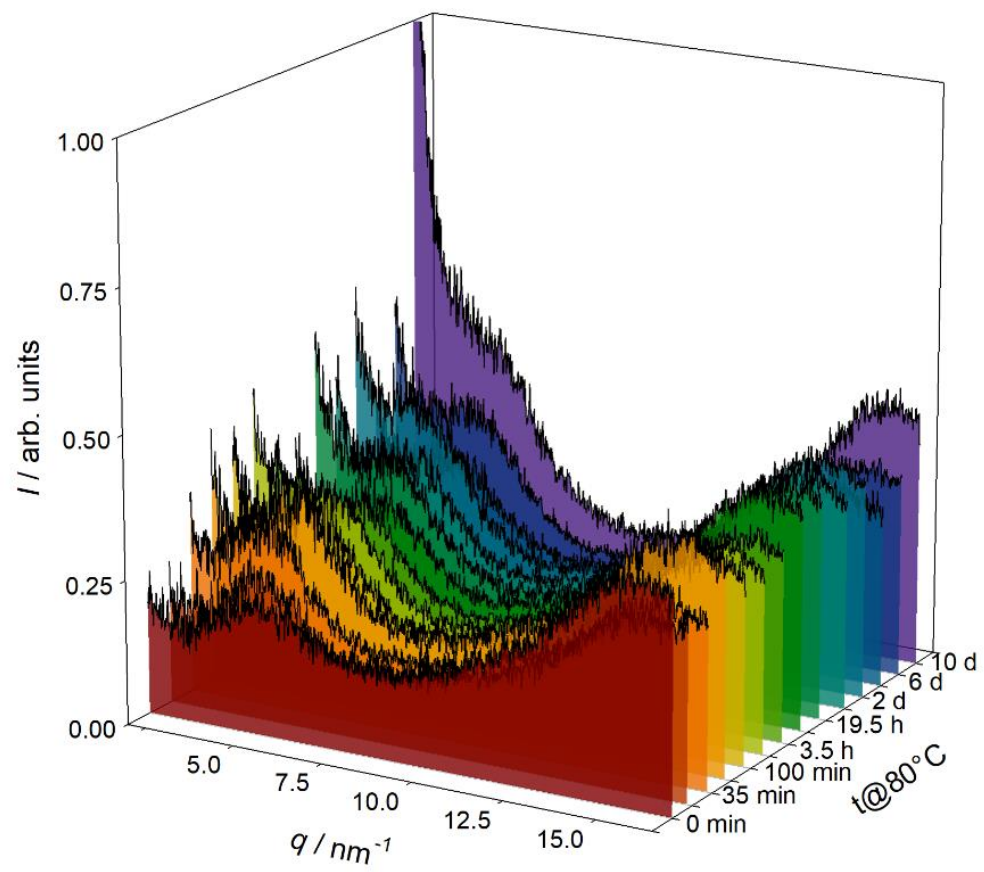

Figure S10. Time-dependent WAXS measurements during the templating process with the $\mathrm{H}_{1}$ phase as parent system, corresponding to the SAXS measurements shown in Figure $3 \mathrm{~b}$. The absence of significant changes of the WAXS pattern during the thermal treatment at $80{ }^{\circ} \mathrm{C}$ suggests that the intra-micellar arrangement of the polymeric surfactant stays more or less the same throughout the whole templating process. 


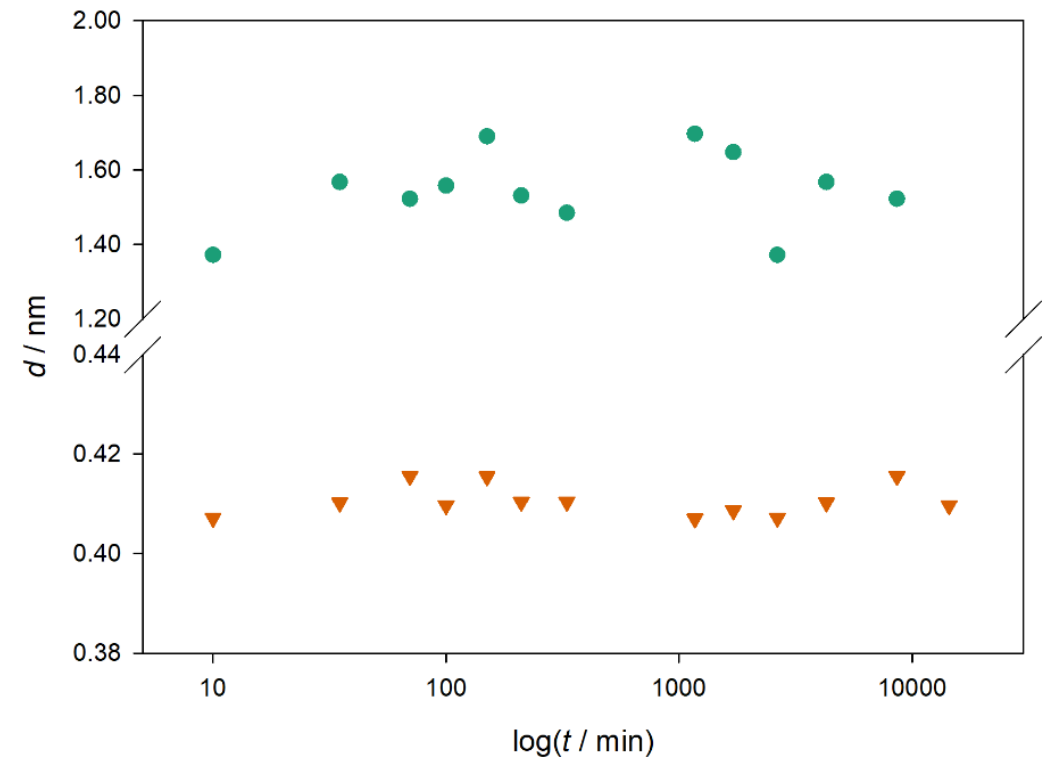

Figure S11. Temporal evolution of the periodicity distance $d$ corresponding to the two diffuse scattering maxima in Figures S10. Due to the different packing densities of the poly(ethylene oxide) and poly(propylene oxide), two scattering maxima occur in the wide-angle region.

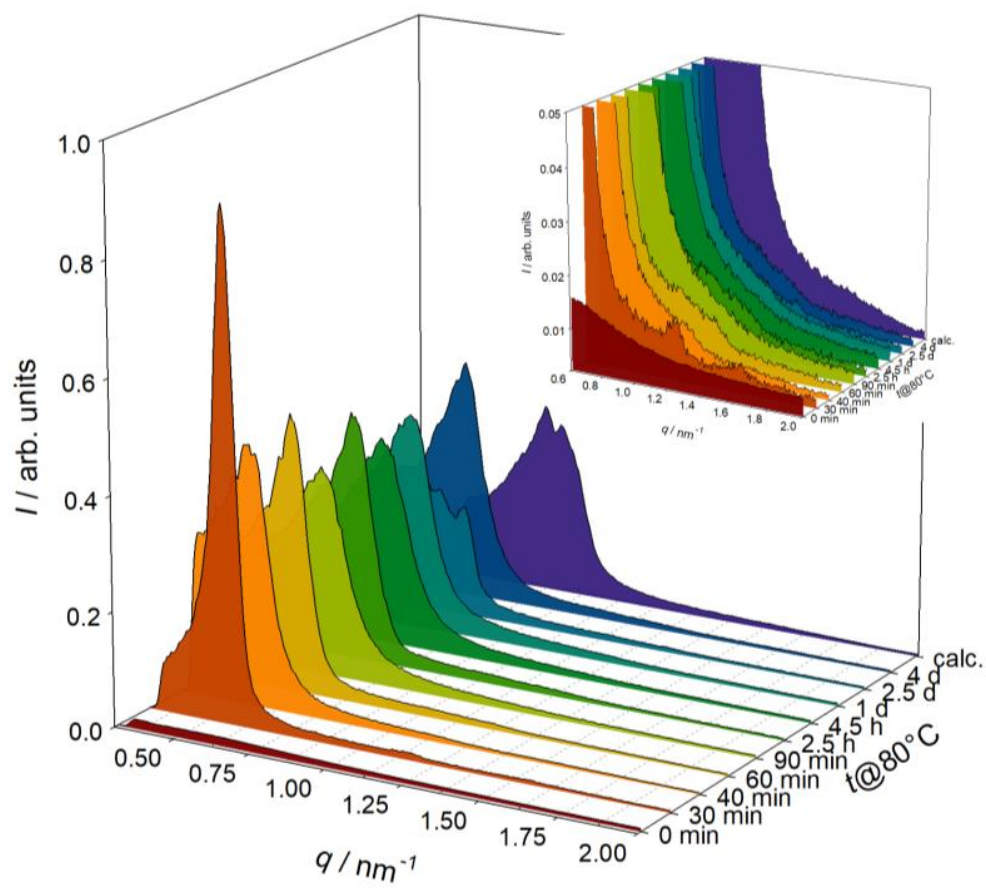

Figure S12. Time-dependent SAXS measurements during the templating process and after calcination with a molar ratio of water to TMOS of 5.1. The parent system is the $\mathrm{H}_{1}$ phase with $w(\mathrm{P} 123)=45$ wt. $\%$. 


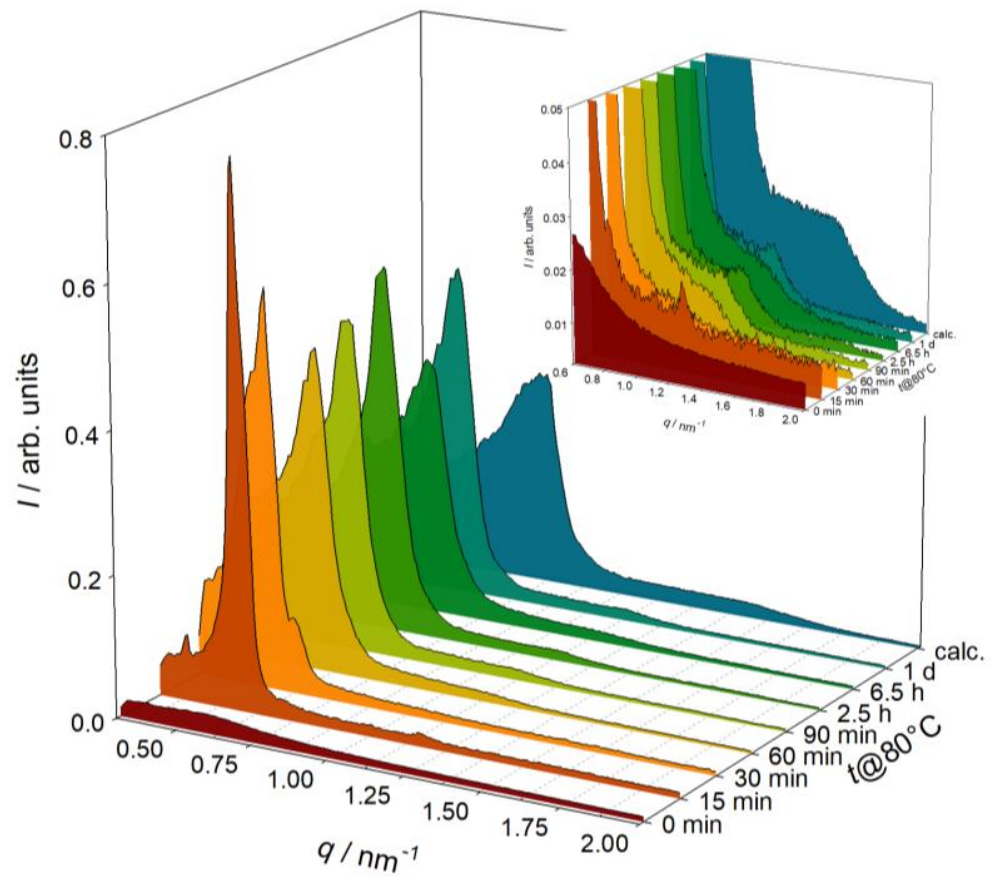

Figure S13. Time-dependent SAXS measurements during the templating process and after calcination with a molar ratio of water to TMOS of 7.1. The parent system is the $\mathrm{H}_{1}$ phase with $w(\mathrm{P} 123)=45$ wt. $\%$ 


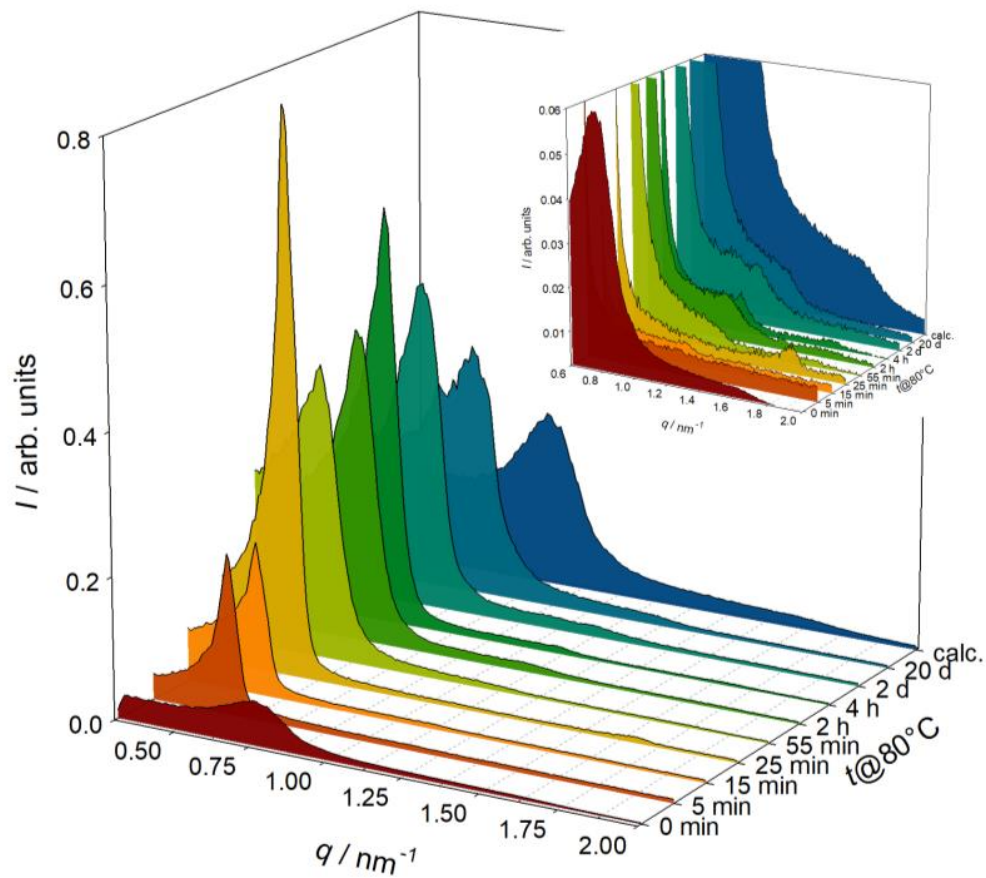

Figure S14. Time-dependent SAXS measurements during the templating process and after calcination with a molar ratio of water to TMOS of 8.7. The parent system is the $\mathrm{H}_{1}$ phase with $w(\mathrm{P} 123)=45$ wt. $\%$ 


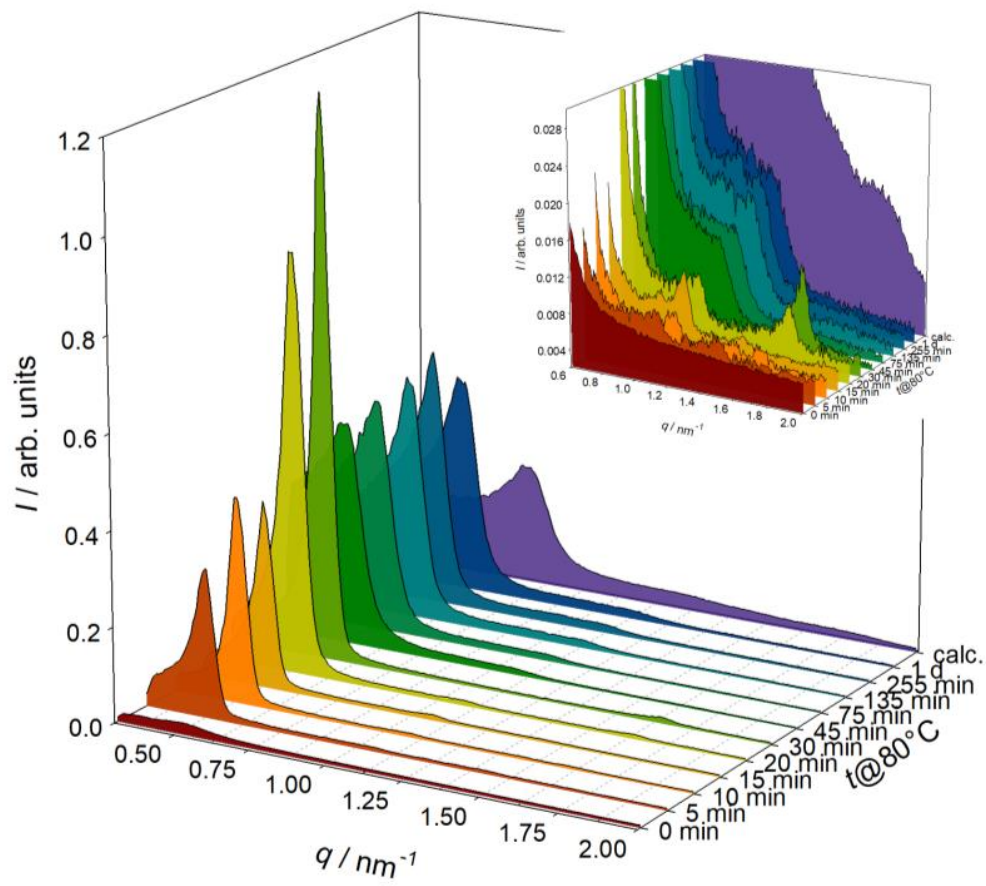

Figure S15. Time-dependent SAXS measurements during the templating process and after calcination with a molar ratio of water to TMOS of 10.7. The parent system is the $\mathrm{H}_{1}$ phase with $w(\mathrm{P} 123)=45$ wt. $\%$

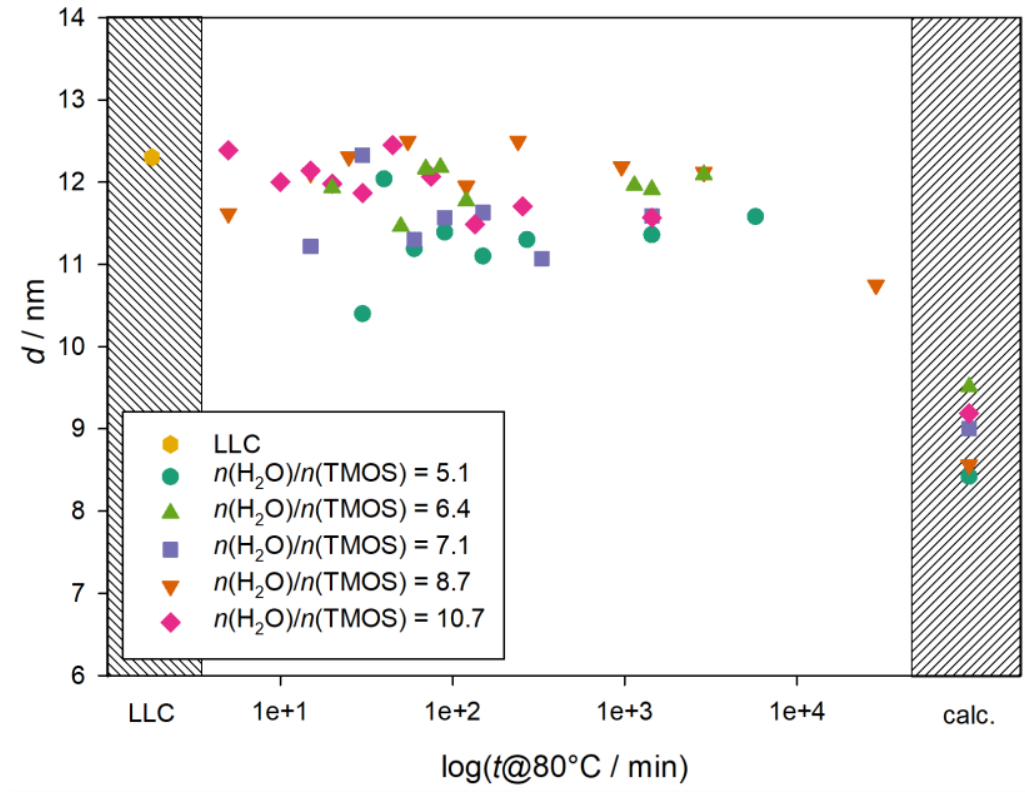

Figure S16. Temporal evolution of the periodicity distance $d$ corresponding to the first scattering maximum in Figures S12 to S15 and Figure 3b. 


\section{Additional transmission electron micrographs}

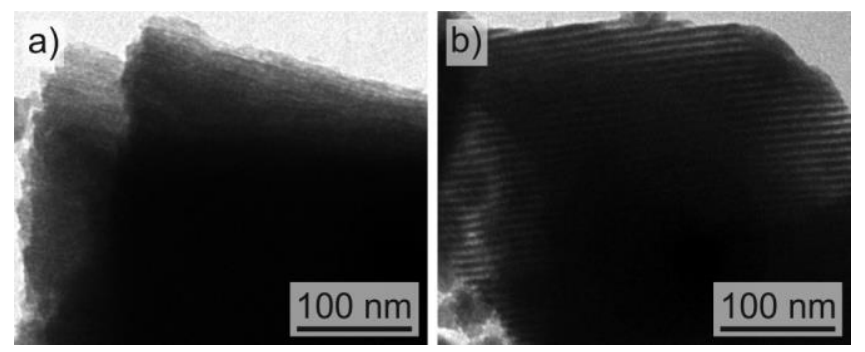

Figure S17. Image of the MSM with the lamellar $\mathrm{L}_{\alpha}$ phase as parent system as seen by TEM. a) Typical micrograph of the sample without any pores visible. However, one may speculate about a sheeted structure when looking at the upper left corner of the image. This structure is in line with the absence of a scattering maximum in SAXS experiments (Figure 5a). b) In very rare regions of the sample parallel pores appear. They resemble the pores found in the hexagonal system (Figure 4b) when seen from the side and might thus be cylindrical. However, there is the possibility, that these pores are indeed slit-shaped, as expected for a MSM templated from a lamellar phase.
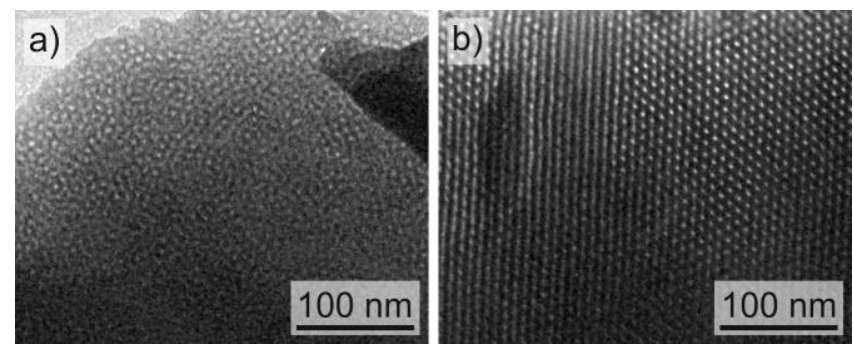

Figure S18. Image of the MSM with the cubic $I_{1}$ phase as parent system as seen by TEM. a) Typical micrograph of the sample with rather evenly sized pores, but without a long-range order of them. This structure is in line with the one scattering maximum found by SAXS measurements (Figure 5c), which reflects the average pore-to-pore distance, but the absence of any further scattering maxima. b) In rare regions of the sample, hexagonally arranged pores appear. They resemble the pores found in the hexagonal system (Figure 4a) when seen from the top. Due to the narrow concentration regime in which the $I_{1}$ phase exists, it seems likely, that even slight inhomogenities in the concentration of the sample might induce a hexagonal structure. 


\section{Nitrogen physisorption measurements}

Table S1. Surface areas, pore volumes and diameters derived from the nitrogen physisorption measurements by different methods. In detail, the following parameters are listed: Surface area determined by the DFT method $\left(S_{\mathrm{DFT}}\right)$, total surface area determined by the BET method $\left(S_{\mathrm{BET}}\right)$, external surface ( $\left.S_{\text {external }}\right)$, surface of the micropores $\left(S_{\text {micro }}\right)$, total pore volume $\left(V_{\mathrm{BET}}\right)$, volume of the micropores $\left(V_{\text {micro }}\right)$, pore diameter determined from the the nitrogen adsorption by the BJH method $\left(d_{\text {pore,BJH }}\right)$, pore diameter determined by the DFT method $\left(d_{\text {pore,DFT }}\right)$.

\begin{tabular}{|c|c|c|c|c|c|c|c|c|}
\hline $\begin{array}{l}\text { Type of } \\
\text { MSM }\end{array}$ & $\begin{array}{c}S_{\mathrm{DFT}} \\
{\left[\mathrm{m}^{2} \mathrm{~g}^{-1}\right]}\end{array}$ & $\begin{array}{c}S_{\mathrm{BET}} \\
{\left[\mathrm{m}^{2} \mathrm{~g}^{-1}\right]}\end{array}$ & $\begin{array}{c}S_{\text {external }} \\
{\left[\mathrm{m}^{2} \mathrm{~g}^{-1}\right]}\end{array}$ & $\begin{array}{c}S_{\text {micro }} \\
{\left[\mathrm{m}^{2} \mathrm{~g}^{-1}\right]}\end{array}$ & $\begin{array}{c}V_{\mathrm{BET}} \\
{\left[\mathrm{ml} \mathrm{g}^{-1}\right]}\end{array}$ & $\begin{array}{c}V_{\text {micro }} \\
{\left[\mathrm{ml} \mathrm{g}^{-1}\right]}\end{array}$ & $\begin{array}{c}d_{\text {pore,BJH }} \\
{[\mathrm{nm}]}\end{array}$ & $\begin{array}{c}d_{\text {pore,DFT }} \\
{[\mathrm{nm}]}\end{array}$ \\
\hline $\begin{array}{l}\mathrm{H}_{1} \text { phase } \\
\text { as parent } \\
\text { system }\end{array}$ & 300 & 334 & 286 & 48 & 0.496 & 0.019 & 5.6 & 6.6 \\
\hline $\begin{array}{c}\text { Commercial } \\
\text { SBA-15 }\end{array}$ & 579 & 576 & 480 & 96 & 1.00 & 0.037 & 8.2 & 7.9 \\
\hline $\begin{array}{c}\mathrm{L}_{\alpha} \text { phase } \\
\text { as parent } \\
\text { system }\end{array}$ & 272 & 340 & 340 & 0 & 0.273 & 0 & 3.0 & 3.8 \\
\hline $\begin{array}{c}\mathrm{I}_{1} \text { phase } \\
\text { as parent } \\
\text { system }\end{array}$ & 2.6 & 31 & 31 & 0 & 0.048 & 0 & 5.1 & 5.9 \\
\hline
\end{tabular}




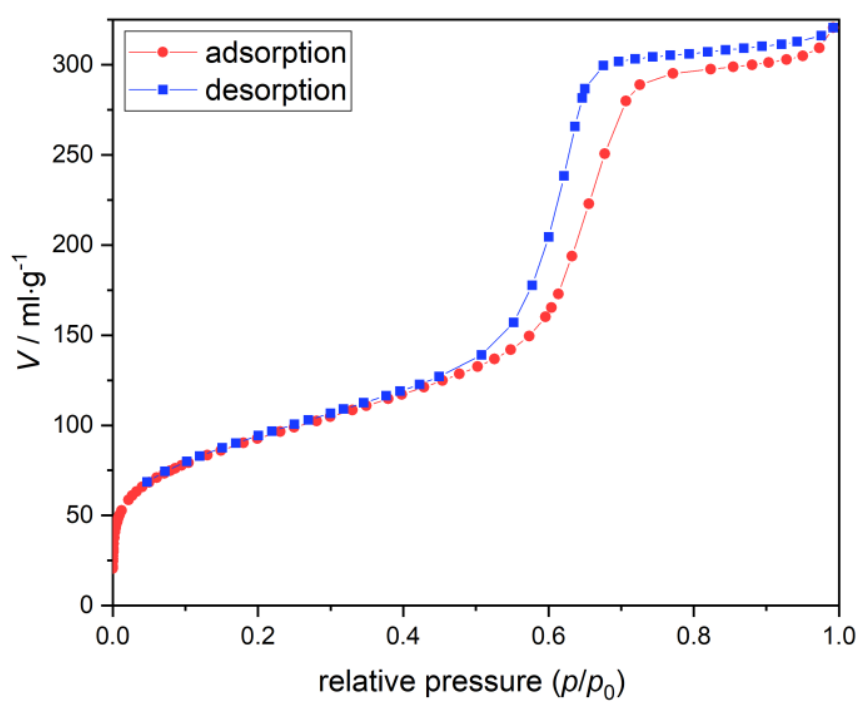

Figure S19. Isotherm of the MSM with the $\mathrm{H}_{1}$ phase as parent system.

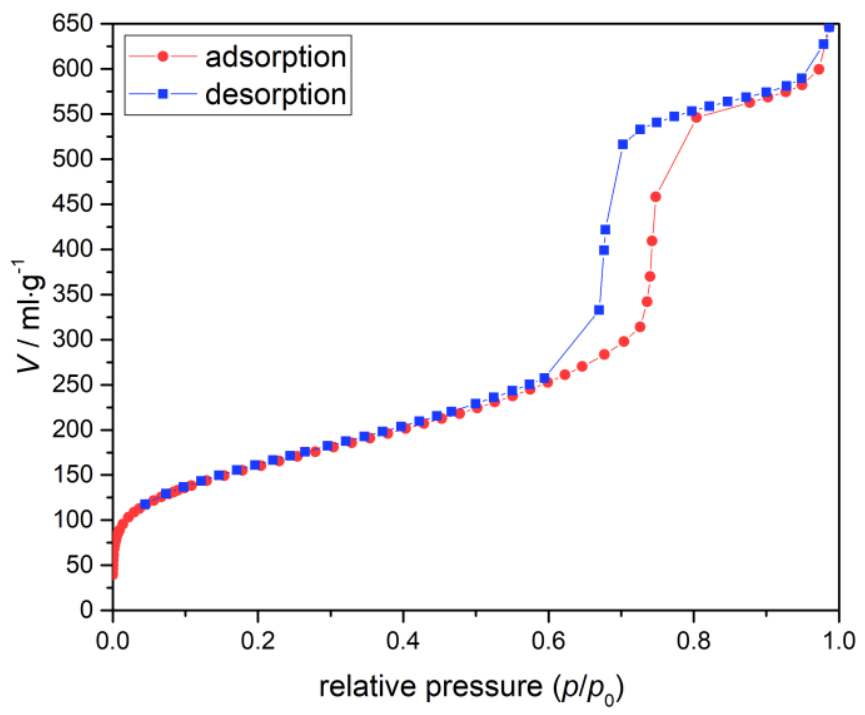

Figure S20. Isotherm of SBA-15 bought from Sigma-Aldrich (Lot \#MKBZ8910V) with a specified particle size less than $150 \mu \mathrm{m}$ and a specified pore size of $8 \mathrm{~nm}$. 


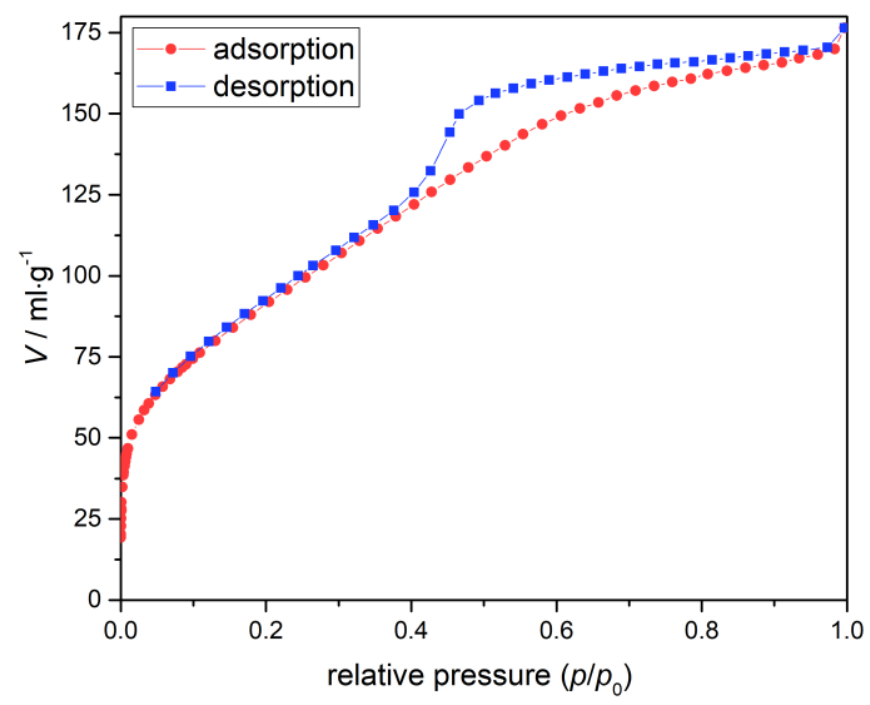

Figure S21. Isotherm of the MSM with the $\mathrm{L}_{\alpha}$ phase as parent system.

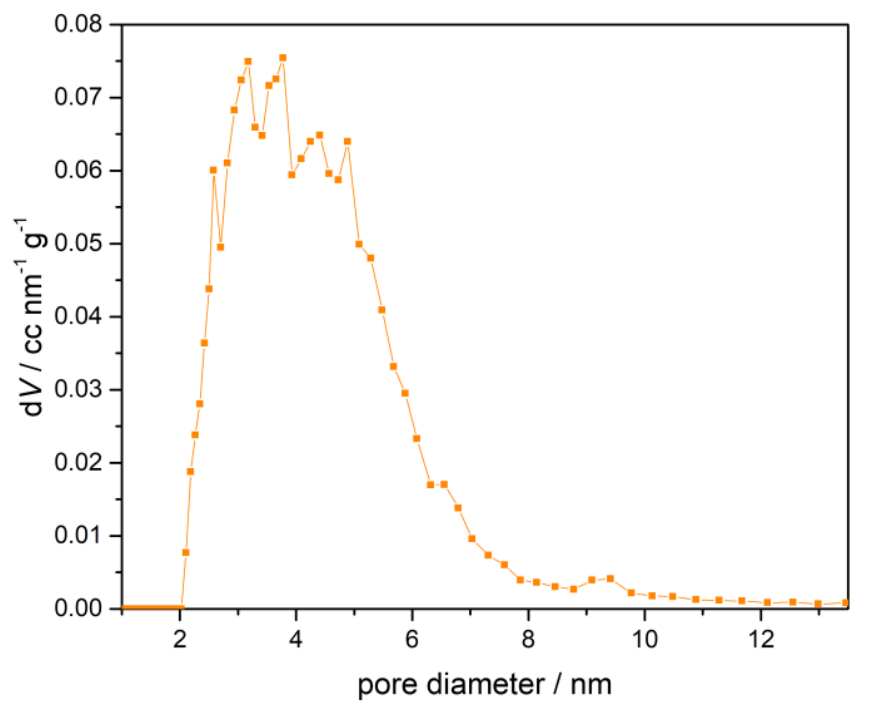

Figure S22. Pore width distribution of the MSM with the $\mathrm{L}_{\alpha}$ phase as parent system as calculated by the DFT method. Even though the DFT method already assumes cylindrical pores and, thus, the BJH method would be more suitable for this sample, we used it here for sake of comparability. 


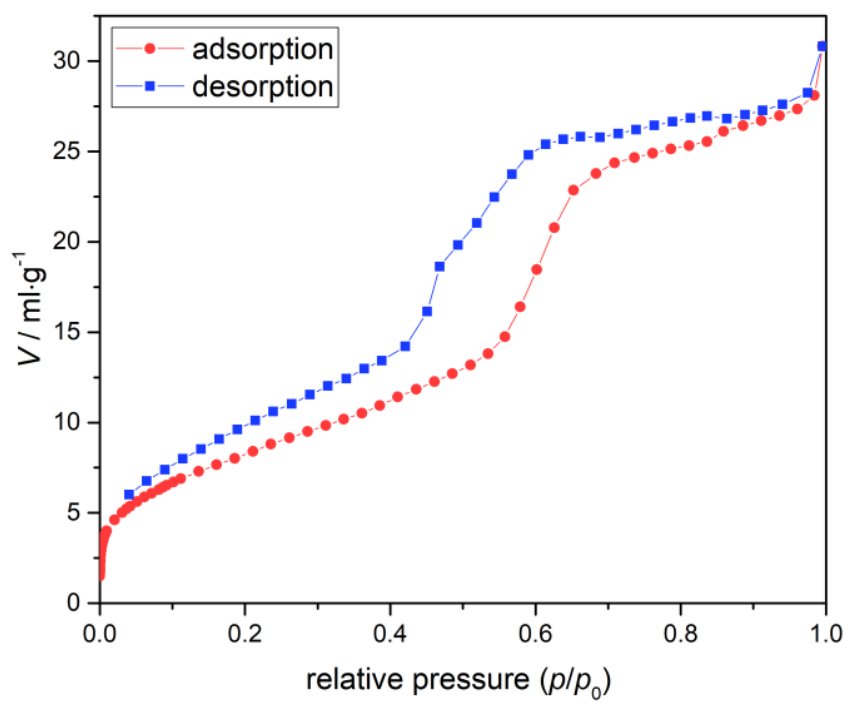

Figure S23. Isotherm of the MSM with the $\mathrm{I}_{1}$ phase as parent system.

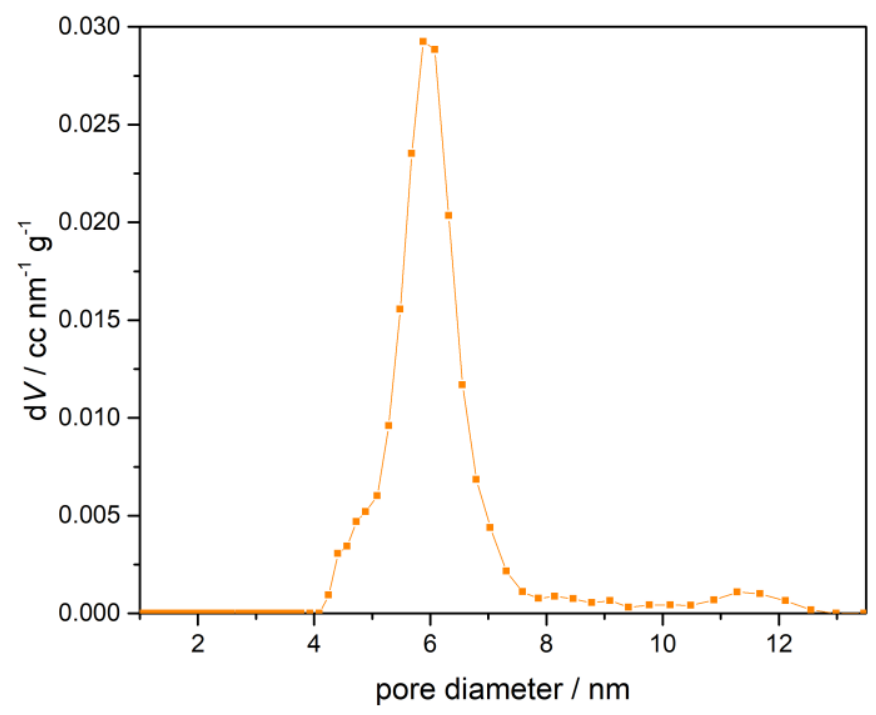

Figure S24. Pore width distribution of the MSM with the $I_{1}$ phase as parent system as calculated by the DFT method. Even though the DFT method already assumes cylindrical pores and, thus, the BJH method would be more suitable for this sample, we used it here for sake of comparability. 


\section{Shrinkage of the lattice parameter}

Table S2. Data used to calculate the theoretical shrinkage according to the equation 9. The given masses $m$ correspond to the experimentally used values, but are normalized to $m(\mathrm{P} 123)=1 \mathrm{~g}$.

\begin{tabular}{c|cccccc}
\hline$\frac{n\left(\mathrm{H}_{2} \mathrm{O}\right)}{n(\mathrm{TMOS})}$ & \multicolumn{3}{|c}{$m / \mathrm{g}$} & & \multicolumn{3}{c}{$\rho / \mathrm{g} \cdot \mathrm{ml}^{-1}$} \\
& $\mathrm{P} 123$ & $\mathrm{H}_{2} \mathrm{O}$ & $\mathrm{SiO}_{2}$ & $\mathrm{P} 123$ & $\mathrm{H}_{2} \mathrm{O}$ & $\mathrm{SiO}_{2}$ \\
\hline 5.1 & 1 & 1.2135 & 0.7941 & 1.018 & 0.997 & 2.196 \\
6.4 & 1 & 1.2227 & 0.6358 & 1.018 & 0.997 & 2.196 \\
7.1 & 1 & 1.1860 & 0.5593 & 1.018 & 0.997 & 2.196 \\
8.7 & 1 & 1.2139 & 0.4651 & 1.018 & 0.997 & 2.196 \\
10.7 & 1 & 1.2203 & 0.3812 & 1.018 & 0.997 & 2.196 \\
\hline
\end{tabular}




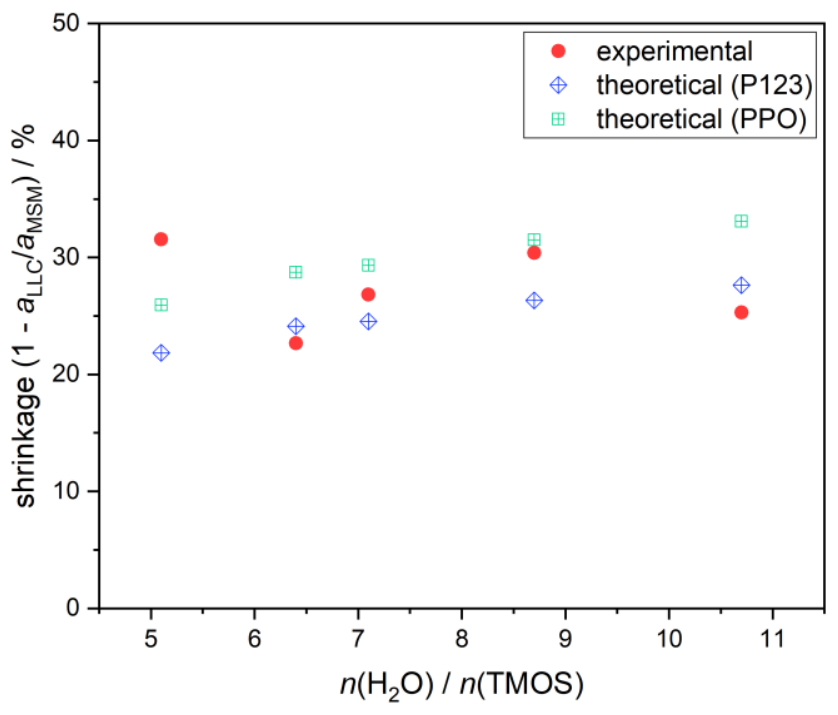

Figure S25. Experimentally obtained shrinkage $1-a_{\mathrm{MSM}} / a_{\mathrm{LLC}}$ (red circles) plotted versus the molar ratio $n_{\mathrm{H} 2 \mathrm{O}} / n_{\mathrm{TMOS}}$, which corresponds to a decrease of $m_{\mathrm{TMOS}} / m_{\mathrm{P} 123}=2$ to $m_{\mathrm{TMOS}} /$ $m_{\mathrm{P} 123}=1$. The theoretical values as calculated from Equation 9 are pictured by blue diamonds. If assuming, that the pore volume $V_{\text {pore }}$ equals the volume of the hydropic parts of the micelles only, i.e. the PPO-moieties instead of the whole surfactant P123, we obtain the theoretical shrinkage plotted as turquoise squares. For this the mass of P123 $m_{\mathrm{P} 123}$ in Equation 9 is replaced by the mass fraction of the PPO-moieties in the surfactant $(\sim 69$ wt.\%). Overall, the experimental and theoretical values match quite well; however, the experimental shrinkage does not comply with the weak theoretical increase with increasing values of $n_{\mathrm{H} 2 \mathrm{O}} / n_{\mathrm{TMOS}}$. We assume that this is due to inevitable slight deviations during the preparation process, e.g. caused by water evaporation, different viscosities and thus mixing qualities, or instrumental errors. 


\section{Calculation of electron density maps}

The electron density $\rho$ at a certain position in 2D space $x y$ relates to the complex scattering amplitude $F(h k)$ via

$$
\rho(x y)=\frac{1}{V} \sum_{h k} F(h k) \cdot \exp [-2 \pi i(h x+k y)],
$$

with the Miller indices $h k$. The scattering amplitude can be split up into its modulus $|F(h k)|$ and a term including its phase angle $\phi(h k)$ :

$$
F(h k)=|F(h k)| \cdot \exp [i \cdot \phi(h k)] .
$$

The square of this modulus connects to the scattered intensity $I(h k)$ via

$$
I(h k)=c \cdot m \cdot A \cdot L \cdot P \cdot|F(h k)|^{2},
$$

where $c$ contains universal constants as well as constants for a given diffraction experiment, $m$ is the multiplicity, which refers to the number of symmetry-equivalent reflections and $A$ is the $\mathrm{X}$ ray absorption. In our experimental set-up the Lorentz factor $\mathrm{L}$ is given by

$$
L=(\sin 2 \theta)^{-1}
$$

and the polarization factor $\mathrm{P}$ by

$$
P=\left(1+\cos ^{2} 2 \theta\right) / 2
$$

with the scattering angle $2 \theta$.

In a first approximation, we assume that the transmitted intensity of the primary beam is the same for all investigated samples, i.e. $c$ and $A$ in Equation $\mathrm{S} 3$ are roughly equal for the samples investigated and the experimental set-up used. Thus, we normalized the primary beam of the Lorentz and polarization corrected scattering data to an intensity value of 1 , before extracting the corrected intensities $I_{c}(h k)$. As can be seen from the according Figure S26, prior to fitting the peak areas, it is still necessary to subtract different base lines from the individual scattering curves. This shows, that the assumption made before is a rather crude estimation and that the calculated electron density maps contain qualitative information, only. 


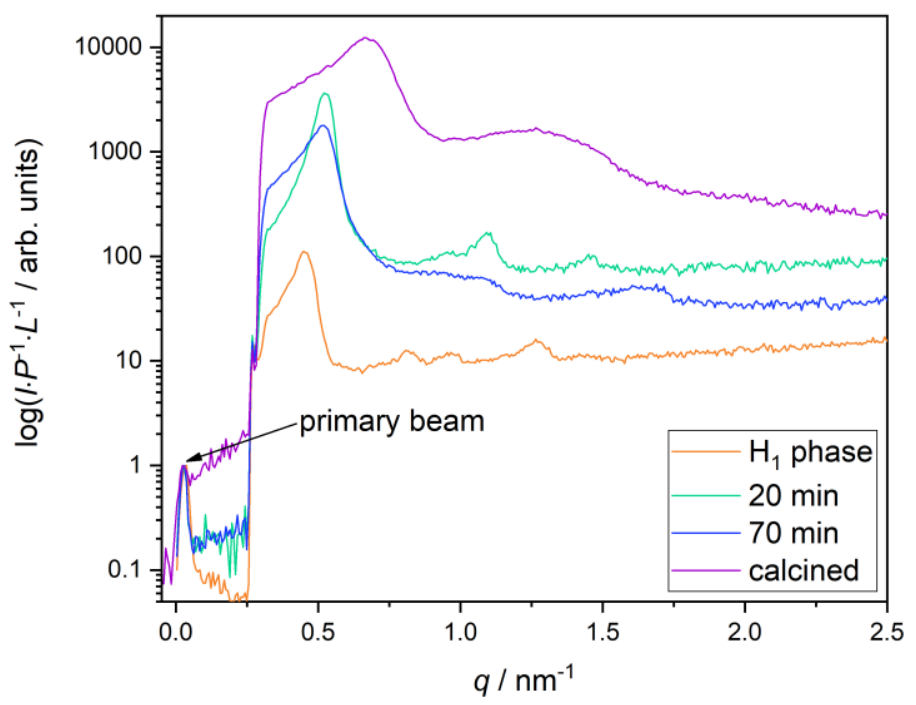

Figure S26. Small angle X-ray scattering curves of the key steps in the true liquid crystal templating process with the $\mathrm{H}_{1}$ phase as parent system (cf. Figure 5 and 7). The intensities are corrected with the Lorentz and the polarization factors and the residual intensity of the primary beam, which passes through the semitransparent beam stop, is normalized to 1 .

The corrected intensities $I_{c}(h k)$ are listed in Table S3 together with the multiplicity $m$ of the respective scattering peak. By combining the Equations S1 to S3 the electron density can be written as

$$
\rho(x y) \propto \sum_{h k} \sqrt{I_{c}(h k) / m} \cdot \exp [-2 \pi i(h x+k y)+i \cdot \phi(h k)]
$$

or as

$$
\rho(x y) \propto \sum_{h k} \sqrt{I_{c}(h k) / m} \cdot \cos [-2 \pi i(h x+k y)+\phi(h k)]
$$

if including Euler's formula and centrosymmetric conditions. With the help of Equation S7, we calculated the electron density maps for every possible combination of the unknown phase angles $\varphi(h k)$ and selected the most likely ones based on their physicochemical plausibility. The result is shown in Figure 7. 
Table S3. Values used for the calculation of the electron density maps depicted in Figure 7.

\begin{tabular}{|c|c|c|c|c|c|}
\hline Sample & $a / \mathrm{nm}$ & $h k$ & $I_{c}(h k)$ & $m$ & $\varphi(h k)$ \\
\hline \multirow{5}{*}{ LLC } & \multirow{5}{*}{14.2} & 10 & $9.97 \cdot 10^{0}$ & 6 & $\pi$ \\
\hline & & 11 & $4.49 \cdot 10^{-1}$ & 6 & 0 \\
\hline & & 20 & $3.76 \cdot 10^{-1}$ & 6 & 0 \\
\hline & & 21 & $6.96 \cdot 10^{-1}$ & 12 & $\pi$ \\
\hline & & 30 & $1.55 \cdot 10^{-1}$ & 6 & $\pi$ \\
\hline \multirow{4}{*}{$\begin{array}{l}\text { HM after } 20 \\
\text { min }\end{array}$} & \multirow{4}{*}{14.1} & 10 & $1.48 \cdot 10^{1}$ & 6 & $\pi$ \\
\hline & & 11 & $2.31 \cdot 10^{-1}$ & 6 & 0 \\
\hline & & 20 & $4.35 \cdot 10^{-1}$ & 6 & 0 \\
\hline & & 21 & $1.21 \cdot 10^{-1}$ & 12 & $\pi$ \\
\hline \multirow{4}{*}{$\begin{array}{l}\text { HM after } 70 \\
\text { min }\end{array}$} & \multirow{4}{*}{14.5} & 10 & $2.63 \cdot 10^{2}$ & 6 & $\pi$ \\
\hline & & 11 & $8.09 \cdot 10^{0}$ & 6 & 0 \\
\hline & & 20 & $6.55 \cdot 10^{0}$ & 6 & 0 \\
\hline & & 21 & $5.65 \cdot 10^{0}$ & 12 & $\pi$ \\
\hline \multirow{4}{*}{$\begin{array}{l}\text { Calcined } \\
\text { MSM }\end{array}$} & \multirow{4}{*}{11.2} & 10 & $4.56 \cdot 10^{3}$ & 6 & $\pi$ \\
\hline & & 11 & $6.89 \cdot 10^{2}$ & 6 & 0 \\
\hline & & 20 & $6.58 \cdot 10^{2}$ & 6 & 0 \\
\hline & & 21 & $1.53 \cdot 10^{2}$ & 12 & $\pi$ \\
\hline
\end{tabular}




\title{
AUTHOR INFORMATION
}

\section{Corresponding Author}

*johanna.bruckner@ipc.uni-stuttgart.de,+49 71168564136

\section{Author Contributions}

The manuscript was written through contributions of all authors. All authors have given approval to the final version of the manuscript.

\begin{abstract}
ABBREVIATIONS
BET, Brunauer-Emmett-Teller; BJH, Barrett-Joyner-Halenda; CCD, charge-coupled device; CMOS, complementary metal-oxide-semiconductor; col.sil., colloidal silica; DFT, density functional theory ; $\mathrm{H}_{1}$, hexagonally ordered LLC phase of rod-shaped, normal micelles (in this context "normal" indicates that the continuous phase surrounding the micelles is hydrophilic, in contrast to "inverse" in which case this phase is lipophilic); HM, hybrid material; $\mathrm{I}_{1}$, cubic LLC phase of spherical, normal micelles; $\mathrm{L}_{\alpha}$, fluid lamellar LLC phase with molten polymer chains; LLC, lyotropic liquid crystal; MSM, mesoporous silica materials; PEO, poly(ethylene oxide); PPO, poly(propylene oxide), SAXS, small-angle X-ray scattering; TEM, transmission electron microscopy; TMOS, tetramethyl orthosilicate; WAXS, wide-angle X-ray scattering
\end{abstract}

\section{ACKNOWLEDGMENT}

We thank Jan Florenski (Institute of Chemical Technology, University of Stuttgart) for the performance of Karl-Fischer-Titrations, Gabriele Bräuning for DSC measurements, Katja Steck for assistance with the rheology measurements (both Institut of Physical Chemistry, University of Stuttgart) as well as Michael Schweikert and Beate Nitschke (Institute of Biomaterials and Biomolecular Systems, University of Stuttgart) for technical assistance with the TEM. Funded by the Deutsche Forschungsgemeinschaft (DFG, German Research Foundation) - Project-ID 358283783 - SFB 1333. 